\title{
Risk Factors Associated with HIV Infection Among Infants Below 24 Months Born to HIV Positive Mothers
}

\author{
Gloria Kirungi Kasozi ${ }^{1, ~ *}$, Afayoa Robert ${ }^{2}$ \\ ${ }^{1}$ Department of Public Health, Faculty of Health Sciences, Uganda Christian University, Mukono, Uganda \\ ${ }^{2}$ Department of Public Health, International Health Sciences University, Kampala, Uganda \\ Email address: \\ gkirungi@gmail.com (G. K. Kasozi) and afayoarbt@yahoo.co.uk (A. Robert) \\ ${ }^{*}$ Corresponding author
}

\section{To cite this article:}

Gloria Kirungi Kasozi, Afayoa Robert. Risk Factors Associated with HIV Infection Among Infants Below 24 Months Born to HIV Positive Mothers. International Journal of HIV/AIDS Prevention, Education and Behavioural Science. Vol. 3, No. 5, 2017, pp. 54-62.

doi: 10.11648/j.ijhpebs.20170305.12

Received: October 13, 2017; Accepted: October 31, 2017; Published: November 30, 2017

\begin{abstract}
In order to eliminate infant HIV infection from mother to child, evidence based implementation strategies are needed to address the risk factors that are associated with this infection using limited resources and applicable to all stakeholders especially the parents of the infants. This study assessed the infant, maternal and paternal risk factors associated with HIV infection among infants below 24 months born to HIV positive mothers in care. An unmatched nested case control study was conducted at the HIV/ART clinic, Mildmay Uganda in 2012. 370 HIV positive mothers with their biological infants below 24 months who had had a DNA-PCR test done in the last 6 months were enrolled in the study (cases: DNA-PCR positive infants, controls: DNA-PCR negative infants). Data was collected using a structured questionnaire. Descriptive, bivariate and multivariate analyses were done. The risk factors that showed a significant relationship with HIV infection of infants below 24 months born to HIV positive mothers were: Infant factors: Infant and young child feeding option used in the first 8 weeks of life $(p<0.001)$ ART status $(p<0.001)$, Immunization status $(p=0.031)$ and duration of receiving Nevirapine syrup of the infant $(\mathrm{p}=0.002)$ significantly increased the risk of infection. Maternal factors: High baseline viral load during pregnancy $(\mathrm{p}=0.046)$, Body Mass Index $>30 \mathrm{~kg} / \mathrm{m} 2(\mathrm{p}=0.008)$, receipt of ART during pregnancy ( $<<0.001)$, receipt of nutrition counseling $(p=0.002)$ and non-disclosure of HIV status to spouse of the mother during pregnancy $(p<0.001)$. Paternal factors: Acceptance to test for HIV $(p<0.001)$, non-disclosure of HIV status to spouse $(p<0.001)$ and receipt of ART ( $<<0.001)$. Multivariate analysis showed a significant relationship with HIV infection of infants who were mixed fed the infant (OR: 4.971, 95\%CI: $1.71-14.48, \mathrm{p}=0.003$ ), receipt of ART (NVP) of the infant (OR: 0.0062, 95\%CI:0.002 - 0.019, p<0.001), mother not disclosing of HIV status to spouse (OR:2.736, 95\%CI:1.074 - 6.971, p=0.035) and Father not disclosing of HIV status to spouse (OR:4.38, 95\%CI:1.764 - 11.235, $\mathrm{p}=0.002)$. The results show that mixed feeding of infants and parental nondisclosure of HIV status are key drivers that significantly increase the risk of infant infection while infant prophylactic Niverapine reduces the risk of infection. It is recommended that exclusively breastfeed of infants born to HIV positive women, HIV testing and spousal disclosure of HIV status be promoted among PLHIV.
\end{abstract}

Keywords: Non-Disclosure, HIV DNA-PCR Test, HIV Infection, Exclusive Breastfeeding, Mixed Feeding, Risk Factors

\section{Introduction}

At the end of 2010, an estimated 34 million people were reported to be living with HIV globally, out of which 3.4 million are children less than 15 years of age. 2.7 million People (1.9million in sub Saharan Africa) were new HIV infections out of which an average of 390,000 were new infections among children less than 15 years [1]. However, in 2016, the estimated number of PLHIV has increased to 36.7 million globally of which 2.1 million are children below 15 years. Out of the 1.8million new HIV infections registered globally, 160,000 are children. [13]. Unfortunately sub Saharan Africa accounts for $90 \%$ new infections and, vertical transmission of HIV still accounts for over 95\% of infant infection with an estimated 1.8million people died from 
AIDS-related causes worldwide, 250,000 of which are children less than 15 years of age [1]. in 2016, 19.4 million people are living with HIV out of which 77,000 are children below 15 years [2]. In Uganda, the prevalence of HIV infection in the central region and Kampala is $8.5 \%(0.7 \%$ among children), $10 \%$ in urban areas compared to rural prevalence of $6 \% 57 \%$ of people living with HIV are women while $13 \%$ are children below 15 years at the time of the study. [3] However, the prevalence of HIV has declined in 2017 to $7.5 \%$ and $5.8 \%$ in urban and rural areas respectively. The prevalence among the target group (below 15 years) is now at $0.5 \%$ [4]. At Mildmay Uganda, approximately 27,000 people are enrolled into care out of which $19 \%$ are children 15 years and below [5]. The Mother to child infection rate was at $4.2 \%$ in 2016 [6]. This disease burden has consequently increased the morbidity and mortality of these vulnerable children while also increasing the cost of care.

A number of risk factors have been associated with vertical transmission such as maternal indicators of disease progression (high viral load, low CD4 count, and viral characteristics) paternal involvement during after pregnancy as well as Infant young child feeding options. [7] These trends have also been linked to the low utilization of medication in resource limited settings, low uptake of HIV and PMTCT services, use of inappropriate infant and young child feeding options, high illiteracy levels, low family planning uptake, poverty and low male partner involvement the men's shared responsibility, their active participation in responsible parenthood, sexual and reproductive behavior including family planning; prenatal, maternal child health; prevention of unwanted and high-risk pregnancies; shared control and contribution to family income, children's education, health and nutrition; recognition and promotion of the equal value of children of both sexes. [8-13].

Prevention of mother to child infection entails acceptance of HIV testing, disclosure of HIV result, having consistent safe sex, ARV treatment for both mother and child, safe infant and young child feeding practices and other supportive decision making and support. [14] Despite the documented evidence on the risk factors associated with HIV infection, limited data exists on the infant, paternal and maternal factors that influence HIV infection among infants born to HIV positive mothers in resource limited settings. The identification of the actual risk factors to infant infection will inform policy makers and help design more effective interventions to eliminate infant infection and hence reducing HIV-related morbidity and, mortality and cost of medical care hence the need for this study to examine the infant, maternal and paternal risk factors that are significantly associated with infant HIV infection.

\section{Materials and Methods}

\subsection{Study Design}

The study was an unmatched nested case control study with the number of controls twice the number of cases. At
Mildmay, all pregnant women are enrolled for PMTCT, provided with highly active antiretroviral therapy (HAART) and followed up through delivery and their infants followed until 24 months when the last HIV confirmatory test is done, both the mother and child are prospectively followed and vital records taken at particular intervals. It is from these cohort participants that this study was conducted on mothers who fulfilled the inclusion criteria. Retrospective data on socio-demographic data, infant, maternal and paternal factors was recorded from the mother; verification of some information was by review of secondary data in existence.

\subsection{Study Area}

The study was carried out at Mildmay Uganda in Wakiso district, Uganda between June and October 2012. The centre provides comprehensive HIV care and treatment using a holistic family-centered approach to approximately 24,000 people out of which 4560 (19\%) are children (0-18 years).

\subsection{Study Population and Selection Criteria}

All HIV positive mothers with infants below 24 months who are receiving care and support at Mildmay Uganda. Inclusion criteria: HIV positive mothers with biological infant (0-24 months), mother who had been in care at Mildmay at least 3 months before conception, infant had at least one DNA-PCR test done and results given to the mother and mother formally consented to participate in the study.

\subsection{Sample Size and Sampling Procedure}

A total of 370 infants were included in the study [15]

Formula

$$
n=\frac{r+1}{r} \frac{(p)(1-p)\left(Z_{\beta}+Z_{\alpha / 2}\right)^{2}}{\left(P_{1}-P_{2}\right)^{2}}
$$

$\mathrm{n}=$ sample size, $(\mathrm{r}+1) / \mathrm{r}=$ ratio of controls to cases, $\mathrm{r}=1, \mathrm{p}$ $=$ a measure of variability ( similar to standard deviation), $\mathrm{Z} \beta$ $=$ Desired statistical power (typically 0.84 for $80 \%$ power), $Z$ $\alpha / 2=$ Desired level of statistical significance (Two-sided significance level $=1.96), \mathrm{OR}=$ Assumed odds ratio of 2.0 or greater is desired, $\mathrm{p} 1-\mathrm{p} 2=$ effect size (the difference is proportion), $\mathrm{P} 2$ = the proportion exposed in the control group $=20 \%, \mathrm{P} 1=$ the proportion of cases exposed is calculated below, average proportion exposed $=(0.33+0.20) / 2=0.265$. The calculated sample size was 362 .

Controls: DNA-PCR Negative infants below 24 months born to HIV positive mothers in care at Mildmay

Cases: DNA-PCR Positive infants below 24 months born to HIV positive mothers in care at Mildmay

Eligible participants were selected purposively and data collection done during the peadiatric clinic days using a structured questionnaire. The infants whose DNA-PCR test result was confirmed negative (by mother's word of mouth, HCT records, records in the infant's file and laboratory records) were enrolled as controls while infants who had their DNA-PCR result confirmed positive were recruited as 
cases. A total of 370 mothers with their biological infants participated, 116 were cases while 254 were controls; they were unmatched and control participants were twice the number of cases.

\subsection{Study Variables}

Dependent variables: Infant DNA-PCR test outcome that has been categorized as DNA-PCR negative and DNAPCR positive.

Independent variables: Infant factors: age, sex, birth weight, Breastfeeding history, IYCF option used and period of receiving NVP syrup of the infant; Maternal factors: age, residence, education level, employment status, marital status, family income, religion, duration of the relationship, acceptance to test for HIV, disclosure of HIV status to spouse, ANC visits made to the health facility, baseline CD4 count, Viral load and receipt of ART and nutrition counselling of the mother during pregnancy. Paternal factors: age, residence, education level, employment status, religion, acceptance to test for HIV, disclosure of HIV status to spouse and receipt of ART

\subsection{Data Sources and Collection}

Primary data was collected from the respondent mothers using a detailed structured questionnaire. information collected included; age of the infant, mother and father, Breastfeeding history, IYCF option used and period of receiving NVP syrup of the infant; residence, education level, employment status, marital status, family income, religion, duration of the relationship, acceptance to test for HIV and disclosure of HIV status of the parents. Secondary data was reviewed and retrieved from patient files, HCT registers, Laboratory records, infant growth monitoring cards, mothers' ANC card, nutrition counseling register and PMTCT register. information retrieved included; birth weight, DNA-PCR test and results of the infants, baseline CD4 count and viral load, receipt of ART and nutrition counseling of the mother during pregnancy.

\subsection{Data Management and Analysis}

Data collection was done by trained interviewers and questionnaire was pre-tested and a preview meeting of the pretest results was done to handle corrections and clarifications before preparing the final questionnaire. The completely filled questionnaires were then coded with numbers $1,2,3 \ldots \mathrm{k}$, variable entry sheet was created and data entered into the variable fields accordingly using SPSS version 20.0 data sheet, upon completion, data was cleaned and then exported to STATA 11.0 software for analysis. All continuous variables such as age, family income were converted into a categorical ordinal scale; other absolute variables were also grouped such as marital status, religion, education status, family planning methods used. All available responses from the interviews were included in the analysis and no sensitivity analyses were done. Logistical regressions were done to determine the statistical significant relationship between the dependent and independent variables in question as well as determining the level of association. During analysis, the association of each exposure variable (independent variable) and the outcome (dependent variable) was determined in cross tabulations. All variables whose p-values were less than 0.2 were considered to be included in the multivariate model; adjusted odds ratios and their respective confidence intervals were obtained and included in the presentation. All statistical tests and their respective confidence intervals were based on a two-tailed test and were performed at the $5 \%$ error rate.

\subsection{Ethical Considerations}

Ethical approval for this study was given by the International Health Sciences University Review Board and Mildmay Uganda Review Board. Written informed consent of all respondents (mothers) was obtained and all information was protected and kept confidential. No videos and photographs of the respondent and their infants were taken and the standard operating procedures at each service delivery points were adhered to. There was no risk to the human subjects participating in the study.

\section{Results}

\subsection{Socio-Demographic Characteristics of Infants and Parents}

\subsubsection{Infants Characteristics}

Table 1. Infants socio-demographic characteristics $(N=370)$.

\begin{tabular}{|c|c|c|}
\hline Variables & $\mathbf{N}$ & Percentage \\
\hline \multicolumn{3}{|l|}{ Age(months) } \\
\hline $0-6$ & 177 & 47.84 \\
\hline$>6$ & 193 & 52.16 \\
\hline \multicolumn{3}{|l|}{ Sex } \\
\hline Male & 156 & 42.70 \\
\hline Female & 212 & 57.30 \\
\hline \multicolumn{3}{|l|}{ Birth weight (kg) } \\
\hline$<2.5$ & 91 & 24.59 \\
\hline$\geq 2.5$ & 279 & 75.41 \\
\hline \multicolumn{3}{|l|}{ Weight for height (\%) } \\
\hline$<70$ & 4 & 1.08 \\
\hline $70-79$ & 30 & 8.11 \\
\hline $80-84$ & 113 & 30.54 \\
\hline$\geq 85$ & 223 & 60.27 \\
\hline \multicolumn{3}{|l|}{ Age at first DNA-PCR test (months) } \\
\hline $0-2$ & 312 & 84.32 \\
\hline$>2$ & 58 & 15.68 \\
\hline \multicolumn{3}{|c|}{ IYCF used in the infant's first 8 weeks } \\
\hline Exclusive breastfeeding & 194 & 52.43 \\
\hline Replacement feeding & 118 & 31.89 \\
\hline Mixed feeding & 56 & 15.14 \\
\hline Pre-heated expressed breast milk & 2 & 0.54 \\
\hline \multicolumn{3}{|l|}{ Duration of receiving ART (weeks) } \\
\hline Never & 39 & 10.54 \\
\hline$<6$ & 63 & 17.03 \\
\hline 6 & 225 & 60.81 \\
\hline$>6$ & 43 & 11.62 \\
\hline \multicolumn{3}{|l|}{ Immunization status } \\
\hline Incomplete & 307 & 82.97 \\
\hline complete & 63 & 17.03 \\
\hline \multicolumn{3}{|l|}{ Infant on ART } \\
\hline Yes & 91 & 24.59 \\
\hline No & 278 & 75.41 \\
\hline
\end{tabular}


Table 1 shows that $57.3 \%(212 / 370)$ of the infants were female, $52 \%$ were aged above 6 months, $75 \%$ weighed $2.5 \mathrm{~kg}$ and above at birth, $60 \%$ of the infants had a weight for height percentage above $85,84 \%$ had had their first DNA-PCR test done and results given to the mother between the age of 0 to 2 months. A large proportion of infants $52.4 \%$ (194) had been exclusively breastfed, while $225(61 \%)$ had received Nevirapine syrup for 6 completed weeks. $83 \%$ of the infants had not completed immunization by the time of the study and $278(75.4 \%)$ were not taking Niverapine at the time of the study.

\subsubsection{Mothers Characteristics}

Table 2. Socio demographic characteristics of the mothers.

\begin{tabular}{|c|c|c|}
\hline Variables & $\mathbf{N}$ & Percentage \\
\hline \multicolumn{3}{|l|}{ Age (years) } \\
\hline $15-24$ & 93 & 25.14 \\
\hline$\geq 25$ & 277 & 74.86 \\
\hline \multicolumn{3}{|l|}{ Body Mass Index $\left(\mathrm{kg} / \mathrm{m}^{2}\right)$} \\
\hline$<18.5$ & 54 & 14.59 \\
\hline $18.5-25$ & 231 & 62.43 \\
\hline$>25$ & 85 & 22.97 \\
\hline $0-350$ & 149 & 40.27 \\
\hline$>350$ & 221 & 59.73 \\
\hline \multicolumn{3}{|l|}{ Baseline Viral load during pregnancy (copies) } \\
\hline Detectable $(>5000)$ & 49 & 13.24 \\
\hline Undetectable $(<5000)$ & 321 & 86.76 \\
\hline \multicolumn{3}{|l|}{ Marital status } \\
\hline Married & 250 & 67.57 \\
\hline \multicolumn{3}{|l|}{ Education level } \\
\hline None & 23 & 6.22 \\
\hline Primary & 144 & 38.92 \\
\hline Secondary & 172 & 46.49 \\
\hline Tertiary & 31 & 8.38 \\
\hline \multicolumn{3}{|l|}{ Duration of the relationship with spouse (years) } \\
\hline $1-3$ & 169 & 45.68 \\
\hline$\geq 4$ & 201 & 54.33 \\
\hline \multicolumn{3}{|l|}{ Religion } \\
\hline Christian & 296 & 80.0 \\
\hline Moslem & 71 & 19.19 \\
\hline Others & 3 & 0.81 \\
\hline \multicolumn{3}{|l|}{ Employment status } \\
\hline Yes & 169 & 45.80 \\
\hline No & 200 & 54.20 \\
\hline \multicolumn{3}{|l|}{ Family planning method in use } \\
\hline Non hormonal (condom, IUD) & 110 & 29.73 \\
\hline \multicolumn{3}{|l|}{ Monthly family income ( shs) } \\
\hline$<100,000$ & 276 & 74.59 \\
\hline$>100,000$ & 94 & 25.41 \\
\hline \multicolumn{3}{|l|}{ Receiving ART during pregnancy } \\
\hline Yes & 299 & 80.81 \\
\hline No & 71 & 19.19 \\
\hline \multicolumn{3}{|l|}{ Test for HIV during pregnancy } \\
\hline Yes & 238 & 64.32 \\
\hline No (before) & 132 & 35.68 \\
\hline \multicolumn{3}{|l|}{ Receive nutrition counseling during pregnancy } \\
\hline Yes & 245 & 66.22 \\
\hline No & 125 & 33.78 \\
\hline \multicolumn{3}{|l|}{ Disclosure of HIV status to spouse } \\
\hline Yes & 293 & 79.19 \\
\hline No & 77 & 20.81 \\
\hline
\end{tabular}

Table 2 shows that $75 \%$ (277/370) of the mothers who participated were aged 25 years and above, $62 \%$ had a body mass index within normal range of $18.5-25 \mathrm{~kg} / \mathrm{m}^{2}, 221$ (59.7\%) had a baseline CD4 count above 350 cells $/ \mathrm{mm}^{3}$ during pregnancy and $321(87 \%)$ had an undetectable viral load copies during pregnancy. Majority $(67.6 \%)$ of the mothers who participated were married, 172 (47\%) had attained secondary level of education, 201 (54\%) reported 
to have had a sexual relationship with the father of the infant for more than four years, $296(80 \%)$ mothers were Christians, $200(54 \%)$ of the mothers were unemployed, $75 \%$ mothers revealed to have a monthly family income less than shs 100,000 . The proportion of mothers who had tested for HIV during pregnancy was 64\% (238) while the rest had tested before pregnancy; however, only 79\% (293) reported to have disclosed their HIV status to their spouses. $139(38 \%)$ of the mothers reported to have used a hormonal method of family planning method before pregnancy, 299 (81\%) mothers had received ART during pregnancy and $66 \%(245)$ reported to have received nutrition counseling during pregnancy

\subsubsection{Fathers Characteristics}

Table 3 shows that out of the 370 mothers who participated, $334(96 \%)$ reported their husbands to be aged 25 years and above, 342 (98\%) were employed and 79 $(23 \%)$ had attained primary level of education. Majority 244 $(70 \%)$ of the fathers were reportedly Christians. The proportion of fathers reported to have tested for HIV when their wives were pregnant was $60 \%$ (209), 59\% (205) fathers had reportedly disclosed their HIV status to their spouse, however, $139(40 \%)$ and $138(40 \%)$ of the mothers did not know the HIV status and ART status of their husbands respectively.

Table 3. Socio-demographic characteristics of fathers.

\begin{tabular}{|c|c|c|}
\hline Variables & $\mathbf{N}$ & Percentage \\
\hline \multicolumn{3}{|l|}{ Age (years) } \\
\hline $15-24$ & 14 & 4.02 \\
\hline$\geq 25$ & 334 & 95.98 \\
\hline \multicolumn{3}{|c|}{ Employment status } \\
\hline Yes & 342 & 98.27 \\
\hline No & 6 & 1.72 \\
\hline \multicolumn{3}{|l|}{ Residence } \\
\hline Kampala & 118 & 33.91 \\
\hline Wakiso & 133 & 38.22 \\
\hline Others & 97 & 27.87 \\
\hline \multicolumn{3}{|c|}{ Test for HIV } \\
\hline Yes & 209 & 60.06 \\
\hline No & 139 & 39.94 \\
\hline \multicolumn{3}{|c|}{ Education level } \\
\hline None & 17 & 4.89 \\
\hline Primary & 79 & 22.70 \\
\hline Secondary & 205 & 58.91 \\
\hline Tertiary & 42 & 12.07 \\
\hline Unknown & 5 & 1.44 \\
\hline \multicolumn{3}{|c|}{ Disclosure of HIV status to spouse } \\
\hline Yes & 205 & 58.91 \\
\hline No & 142 & 40.80 \\
\hline \multicolumn{3}{|l|}{ HIV status } \\
\hline Negative & 73 & 20.98 \\
\hline Positive & 136 & 39.08 \\
\hline Unknown & 139 & 39.94 \\
\hline \multicolumn{3}{|c|}{ Receiving ART } \\
\hline Yes & 102 & 29.31 \\
\hline No & 108 & 31.03 \\
\hline Unknown & 138 & 39.66 \\
\hline \multicolumn{3}{|l|}{ Religion } \\
\hline Christian & 244 & 70.11 \\
\hline Moslem & 104 & 29.89 \\
\hline
\end{tabular}

\subsection{Bivariate Analyses}

\subsubsection{Infant Factors Influencing HIV Infection Among Infants Below 24 Months Born to HIV Positive Mothers}

Table 4 reveals that there is a significant association between the age $(\mathrm{P}=0.01)$, gender $(\mathrm{P}=0.09)$, age at first DNA -PCR test $(\mathrm{P}<0.001)$, Infant and young child feeding option used in the first 8 weeks of life $(p<0.001)$ ART status $(p<0.001)$, Immunization status $(p=0.031)$, duration of receiving Nevirapine syrup of the infant $(p=0.002)$ and HIV infection among infants below 24 months born to HIV positive mothers. However, there is no statistically significant association between the birth weight $(\mathrm{P}=0.096)$, weight for height percentage $(\mathrm{P}=0.506)$ of the infant and HIV infection among infants below 24 months born to HIV positive mothers 
Table 4. Infant risk factors.

\begin{tabular}{|c|c|c|c|c|c|}
\hline Variables & $\mathbf{N}(\%)$ & Controls (\%) & Cases (\%) & $\mathrm{X}^{2}$ & P-value \\
\hline \multicolumn{6}{|l|}{ Age(months) } \\
\hline $0-6$ & $177(47.84)$ & $133(52.36)$ & $44(37.93)$ & 6.646 & 0.01 \\
\hline$>6$ & $193(52.16)$ & $121(47.64)$ & $72(62.07)$ & & \\
\hline \multicolumn{6}{|l|}{ Sex } \\
\hline Male & $158(42.70)$ & 97(38.19) & $61(52.59)$ & 6.7462 & 0.009 \\
\hline Female & $212(57.30)$ & $157(61.81)$ & $55(47.41)$ & & \\
\hline \multicolumn{6}{|l|}{ Birth weight (kg) } \\
\hline$<2.5$ & 91(24.59) & $68(26.77)$ & $23(19.24)$ & 4.6938 & 0.096 \\
\hline$\geq 2.5$ & $279(75.41)$ & $186(73.23)$ & $93(80.17)$ & & \\
\hline \multicolumn{6}{|l|}{ Weight for height (\%) } \\
\hline$<70$ & $4(1.08)$ & $3(1.18)$ & $1(0.86)$ & 2.3358 & 0.506 \\
\hline 70-79 & $30(8.11)$ & $17(6.69)$ & 13(11.21) & & \\
\hline $80-84$ & $113(30.54)$ & $80(31.50)$ & $33(23.45)$ & & \\
\hline$\geq 85$ & $223(60.27)$ & $154(60.63)$ & $69(59.48)$ & & \\
\hline \multicolumn{6}{|c|}{ Age at first DNA-PCR test (months) } \\
\hline $0-2$ & $312(84.32)$ & $238(93.70)$ & $74(63.79)$ & 53.8861 & $<0.001$ \\
\hline$>2$ & $58(15.68)$ & $16(6.30)$ & $42(36.21)$ & & \\
\hline \multicolumn{6}{|c|}{ IYCF used in the infant's first 8 weeks } \\
\hline Exclusive breastfeeding & 194(52.43) & 161(63.39) & $33(28.45)$ & 69.6562 & $<0.001$ \\
\hline Replacement feeding & $118(31.89)$ & $77(30.31)$ & $41(35.34)$ & & \\
\hline Mixed feeding & $56(15.14)$ & $14(5.51)$ & $42(36.21)$ & & \\
\hline Pre-heated expressed breast milk & $2(0.54)$ & $2(0.79)$ & $0(0)$ & & \\
\hline \multicolumn{6}{|c|}{ Duration of receiving Nevirapine (weeks) } \\
\hline Never & $39(10.54)$ & $17(6.69)$ & $22(18.97)$ & 15.1167 & 0.002 \\
\hline$<6$ & $63(17.03)$ & $40(15.75)$ & $23(19.83)$ & & \\
\hline 6 & $225(60.81)$ & $165(64.96)$ & $60(51.72)$ & & \\
\hline \multicolumn{6}{|l|}{ Immunization status } \\
\hline Incomplete & $307(82.97)$ & $218(85.83)$ & $89(76.72)$ & 4.6703 & 0.031 \\
\hline Complete & $63(17.03)$ & $36(14.17)$ & $27(23.28)$ & & \\
\hline \multicolumn{6}{|l|}{ Infant on ART } \\
\hline Yes & $91(24.59)$ & $5(1.97)$ & $86(74.14)$ & 223.6964 & $<0.001$ \\
\hline No & $278(75.41)$ & $249(98.03)$ & $30(25.86)$ & & \\
\hline
\end{tabular}

\subsubsection{Maternal Factors Influencing HIV Infection Among Infants Below 24 Months Born to HIV Positive Mothers}

Table 5 reveals that there is a significant association between HIV infant infection and key maternal factors which include baseline viral load during pregnancy $(\mathrm{p}=0.046)$, receipt of ART during pregnancy $(\mathrm{p}<0.001)$, receipt of nutrition counseling $(\mathrm{p}=0.002)$, disclosure of HIV status to spouse of the mother during pregnancy $(p<0.001)$. However, there is no statistically significant association between HIV infant infection and the maternal age $(\mathrm{p}=0.211)$, baseline CD4 count during pregnancy $(\mathrm{p}=0.333)$, marital status $(\mathrm{p}=0.152)$, education status $(\mathrm{p}=0.972)$, duration of the relationship with the spouse $(\mathrm{p}=0.280)$, religion $(\mathrm{p}=0.225)$, employment status $(\mathrm{p}=0.599)$, family planning method $(\mathrm{p}=0.245)$, monthly family income ( $\mathrm{p}=0.123)$, acceptance to test for $\operatorname{HIV}(\mathrm{p}=0.193)$.

Table 5. Maternal risk factors.

\begin{tabular}{|c|c|c|c|c|c|}
\hline Variables & $\mathbf{N}(\%)$ & Controls (\%) & Cases $(\%)$ & $\mathrm{X} 2$ & P-value \\
\hline \multicolumn{6}{|l|}{ Age (years) } \\
\hline $15-24$ & $93(25.14)$ & $59(23.23)$ & $34(29.31)$ & 1.5654 & 0.211 \\
\hline$\geq 25$ & $277(74.86)$ & $195(76.77$ & $82(70.69)$ & & \\
\hline$<18.5$ & $54(14.59)$ & $28(11.02)$ & $26(22.41)$ & 9.6131 & 0.008 \\
\hline $18.5-25$ & $231(62.43)$ & $161(63.39)$ & $70(60.34)$ & & \\
\hline$>25$ & $85(22.97)$ & $65(25.59)$ & $20(17.24)$ & & \\
\hline \multicolumn{6}{|c|}{ Baseline CD4 count during pregnancy (cells $/ \mathrm{mm} 3$ ) } \\
\hline $0-350$ & $149(40.27)$ & $102(40.16)$ & $47(40.52)$ & 2.1964 & 0.333 \\
\hline$>350$ & $221(59.73)$ & $152(59.84)$ & $69(59.48)$ & & \\
\hline \multicolumn{6}{|l|}{ Baseline Viral load during pregnancy (copies) } \\
\hline Detectable $(>5000)$ & $49(13.24)$ & $39(15.35)$ & $10(8.62)$ & 6.1473 & 0.046 \\
\hline Undetectable $(<5000)$ & $321(86.76)$ & $215(84.65)$ & $106(91.38)$ & & \\
\hline \multicolumn{6}{|l|}{ Marital status } \\
\hline Married & $250(67.57)$ & $167(65.75)$ & $83(71.55)$ & 5.2839 & 0.152 \\
\hline Not married (Divorced, widowed, separated) & $120(32.43)$ & $87(34.25)$ & $33(28.45)$ & & \\
\hline \multicolumn{6}{|l|}{ Education level } \\
\hline None & $23(6.22)$ & $16(6.30)$ & $7(6.03)$ & 0.2318 & 0.972 \\
\hline Primary & $144(38.92)$ & $97(38.19)$ & $47(40.52)$ & & \\
\hline
\end{tabular}




\begin{tabular}{|c|c|c|c|c|c|}
\hline Variables & $\mathbf{N}(\%)$ & Controls (\%) & Cases (\%) & $\mathrm{X} 2$ & P-value \\
\hline Secondary & 172(46.49) & $120(47.24)$ & $52(44.83)$ & & \\
\hline Tertiary & $31(8.38)$ & $21(8.27)$ & $10(8.62)$ & & \\
\hline \multicolumn{6}{|c|}{ Duration of the relationship with spouse (years) } \\
\hline $1-3$ & $169(45.68)$ & 113(44.49) & $56(48.28)$ & 2.5447 & 0.280 \\
\hline$\geq 4$ & $201(54.33)$ & $141(55.51)$ & $60(51.72)$ & & \\
\hline \multicolumn{6}{|l|}{ Religion } \\
\hline Christian & $296(80.0)$ & 198(77.95) & $98(84.48)$ & 2.9818 & 0.225 \\
\hline Moslem & 71(19.19) & $53(20.87)$ & $18(15.52)$ & & \\
\hline Others & $3(0.81)$ & $3(1.18)$ & $0(0.0)$ & & \\
\hline \multicolumn{6}{|l|}{ Employment status } \\
\hline Yes & $169(45.80)$ & 114(44.88) & $55(47.83)$ & 0.2764 & 0.599 \\
\hline No & $200(54.20)$ & $140(55.12)$ & $60(52.17)$ & & \\
\hline \multicolumn{6}{|l|}{ Family planning method in use } \\
\hline None & $121(32.70)$ & $82(32.28)$ & $39(33.62)$ & 7.9062 & 0.245 \\
\hline Hormonal (Norplant, pills, inject - plan) & $139(37.57))$ & 99(38.97) & $40(34.48)$ & & \\
\hline Non hormonal (condom, IUD) & $110(29.73)$ & 73(28.74) & $37(31.9)$ & & \\
\hline \multicolumn{6}{|l|}{ Family income } \\
\hline$<100,000$ & 276(74.59) & 184(72.44) & 92(79.31) & 4.1895 & 0.123 \\
\hline$>100,000$ & $94(25.41)$ & $70(27.56)$ & $25(20.69)$ & & \\
\hline \multicolumn{6}{|l|}{ Mother receiving ART during pregnancy } \\
\hline Yes & 299(80.81) & 224(88.19) & 75(64.66) & 28.4412 & $<0.001$ \\
\hline No & $71(19.19)$ & $30(11.81)$ & $41(35.34)$ & & \\
\hline \multicolumn{6}{|l|}{ Mother test for HIV during pregnancy } \\
\hline Yes & $238(64.32)$ & $156(61.42)$ & $82(70.69)$ & 3.2941 & 0.193 \\
\hline No (before) & $132(35.68)$ & $98(38.58)$ & $34(29.31)$ & & \\
\hline \multicolumn{6}{|c|}{ Receive nutrition counseling during pregnancy } \\
\hline Yes & $245(66.22)$ & 181(71.26) & 64(55.17) & 9.2128 & 0.002 \\
\hline No & 125(33.78) & $74(28.74)$ & $52(44.83)$ & & \\
\hline \multicolumn{6}{|l|}{ Disclosure of HIV status to spouse } \\
\hline Yes & 293(79.19) & $216(85.04)$ & $77(66.83)$ & 16.8252 & $<0.001$ \\
\hline No & $77(20.81)$ & $38(14.96)$ & $39(33.62)$ & & \\
\hline
\end{tabular}

\subsubsection{Paternal Factors Influencing HIV Infection Among Infants Below 24 Months Born to HIV Positive Mothers}

Table 6 shows that there was a significant association between HIV infection of infants and key paternal variables which include; acceptance to test for $\operatorname{HIV}(p<0.001)$, HIV status $(p<0.001)$, disclosure of HIV status to spouse $(p<0.001)$, receipt of ART $(p<0.001)$. However, there is no statistically significant association between HIV infection of infants and the paternal age $(\mathrm{p}=0.428)$, employment status $(p=0.632)$, residence $(p=0.358)$, education level $(p=0.078)$, religion $(\mathrm{p}=0.182)$.

Table 6. Paternal risk factors.

\begin{tabular}{|c|c|c|c|c|c|}
\hline Variables & N (\%) & Controls (\%) & Cases (\%) & $X^{2}$ & P-value \\
\hline \multicolumn{6}{|l|}{ Age (years) } \\
\hline $15-24$ & $14(4.02)$ & $11(4.58)$ & $3(2.78)$ & 0.6289 & 0.428 \\
\hline$\geq 25$ & $334(95.98)$ & $229(95.42)$ & $105(97.22)$ & & \\
\hline \multicolumn{6}{|c|}{ Employment status } \\
\hline Yes & $342(98.27)$ & $236(98.33)$ & $106(98.15)$ & 0.9180 & 0.632 \\
\hline No & $6(1.72)$ & $4(1.67)$ & $2(1.85)$ & & \\
\hline \multicolumn{6}{|l|}{ Residence } \\
\hline Wakiso & $133(38.22)$ & $86(35.83)$ & $47(43.52)$ & & \\
\hline Others & $97(27.87)$ & $68(28.33)$ & $29(26.85)$ & & \\
\hline \multicolumn{6}{|c|}{ Test for HIV } \\
\hline Yes & $209(60.06)$ & $159(66.25)$ & $50(46.30)$ & 12.3623 & $<0.001$ \\
\hline No & $139(39.94)$ & $81(33.75)$ & $58(53.70)$ & & \\
\hline \multicolumn{6}{|c|}{ Education level } \\
\hline None & $17(4.89)$ & $13(5.42)$ & $4(3.70)$ & 8.3904 & 0.078 \\
\hline Tertiary & $42(12.07)$ & $26(10.83)$ & $16(14.81)$ & & \\
\hline Unknown & $5(1.44)$ & $1(0.42)$ & $4(3.70)$ & & \\
\hline \multicolumn{6}{|c|}{ Disclosure of HIV status to spouse } \\
\hline Yes & $205(58.91)$ & $161(67.08)$ & $44(40.74)$ & 22.2946 & $<0.001$ \\
\hline No & $142(40.80)$ & $78(32.50)$ & $64(59.26)$ & & \\
\hline \multicolumn{6}{|l|}{ HIV status } \\
\hline Negative & $73(20.98)$ & $66(27.50)$ & $7(6.48)$ & 29.5546 & $<0.001$ \\
\hline
\end{tabular}




\begin{tabular}{|c|c|c|c|c|c|}
\hline Variables & N (\%) & Controls (\%) & Cases (\%) & $X^{2}$ & P-value \\
\hline Positive & $136(39.08)$ & $98(40.83)$ & $38(35.19)$ & & \\
\hline Unknown & $139(39.94)$ & $76(31.67)$ & 63(58.33) & & \\
\hline \multicolumn{6}{|c|}{ Receiving ART } \\
\hline Yes & $102(29.31)$ & $68(28.33)$ & $34(31.48)$ & 32.7266 & $<0.001$ \\
\hline No & $108(31.03)$ & $96(40.0)$ & $12(11.11)$ & & \\
\hline \multicolumn{6}{|l|}{ Religion } \\
\hline Unknown & $138(39.66)$ & $76(31.67)$ & $62(57.41)$ & & \\
\hline Christian & $244(70.11)$ & $163(67.92)$ & $81(75.0)$ & 1.7835 & 0.182 \\
\hline Moslem & $104(29.89)$ & $77(32.08)$ & $27(25.00)$ & & \\
\hline
\end{tabular}

\subsection{Multivariate Analysis of Factors Associated with Infant HIV Infection}

Table 7 shows that the infants who were exclusively breastfed were 5 times less likely to be infected with HIV from their HIV positive mothers than those who were mixed fed. (OR: 4.971, 95\%CI: 1.71 - 14.48). Infants who were receiving ART (Nevirapine) up to 12 months were less likely to be infected with HIV from the HIV positive mothers than those who were not receiving ART up to 12 months. (OR: $0.0062,95 \%$ CI: $0.002-0.019$ ). Infants whose
HIV positive mothers did not disclose their HIV status to their husbands were three times more likely to acquire HIV infection than infants whose HIV positive mothers disclosed their HIV status to their husbands. (OR:2.736, 95\%CI:1.074 - 6.971). Infants whose fathers did not disclose their HIV status to their wives were four times more likely to acquire HIV infection than infants whose fathers disclosed their HIV status to their wives. (OR:4.38, 95\%CI:1.764 - 11.235)

Table 7. Multivariate analysis of the significant risk factors.

\begin{tabular}{llll}
\hline Variable & N (\%) & OR (95\% CI) & P-value \\
\hline IYCF options used & & & \\
Exclusive Breastfeeding & $194(52.43)$ & $1(\mathrm{ref})$ & 0.003 \\
Mixed feeding & $56(15.14)$ & $4.971(1.71-14.48)$ & 0.000 \\
Infant on ART & & & $0.0062(0.002-0.019)$ \\
Yes & $91(24.59)$ & $1(\mathrm{ref})$ & 1 (ref) \\
No & $278(72.14)$ & $2.736(1.074-6.971)$ & 0.035 \\
Mother's disclosure of HIV status to spouse & $293(79.19)$ & & \\
Yes & $77(20.81)$ & \\
No & $205(58.91)$ & $1(\mathrm{ref})$ & 0.002 \\
Father's disclosure of HIV status to spouse & $142(40.80)$ & $4.38(1.764-11.235)$ & \\
Yes & & & \\
No & &
\end{tabular}

\section{Discussion}

Infant factors: Infants who were mixed fed were five times more likely to acquire HIV from the mother than an infants who were exclusively breastfed. That means that exclusively breastfed infants had lower risk of HIV infection than an infant who mixed fed. Mixed feeding which entails feeding the infant on both breast milk and other foods such as cow's milk, formula milk, juice, porridge, soup and water predisposes the infant to infection because other feeds other than breast milk when provided to an infant below 6 months have been associated with an increased likelihood of damaging and irritating the epithelial integrity of the infant's intestine as well as triggering food allergic reactions and illnesses such as diarrhea, hence infants who are mixed fed are at a high risk of exposure through breast milk and consequences of other feeds [7]. Studies have reported significantly high risk of HIV transmission rate among the infants who are mixed fed although other studies reported no significant difference in the risk of infection between exclusively breastfeeding and mixed fed infants $[16,17]$. Infants who had their first DNA-PCR test done below 8 weeks had a lower risk of infection than those who tested later, this can be linked to the parents of the infant being responsible about their infants health, meaning that they have good medical care-seeking behavior together w ith those whose infants had completed immunization on time, therefore infant HIV infection may also be linked to behavior of the parents in seeking medical care and following medical prescriptions and instructions.

Maternal and male partner factors: Infants whose HIV positive mothers did not disclose their HIV status to their husbands were three times more likely to acquire HIV than the infants whose HIV positive mothers disclosed their HIV status. There is often significant partner support ranging from financial support, medication reminders, provision of adequate food at home to making vital decisions especially regarding the feeding options for the infant. A study in Zimbabwe revealed that the enrolment into the PMTCT program without disclosure exposed the infant to HIV infection as mothers found it hard to exclusively breastfeed and negotiate condom use during pregnancy and lactation. A strong relationship between mode of infant feeding and spouse's awareness was also reported because mothers who had disclosed their HIV status to their spouses were more likely not to breastfeed 
their infants than mothers who had not disclosed their status [19]. Infants whose fathers did not disclose their HIV status to their wives were four times more likely to acquire HIV infection than infants whose fathers disclosed their HIV status to their wives. No studies were found at the time of the study on male partner disclosure in association with infant HIV infection.

\section{Limitations}

The results of this study may be generalized to infants below 24 months born to HIV positive mothers enrolled and active in HIV/ART care. Paternal information included was provided by the mother therefore, it may be possible that mothers did not provided correct spousal information especially regarding HIV testing.

\section{Conclusions}

The results of the study show that the HIV exposed infants who had a high risk of acquiring HIV were those that had been mixed fed during the first 8 weeks of life and those whose parents did not disclose their HIV status to the spouses while the infants who had a very low risk of infection were those who had received Niverapine syrup for the first 6 weeks of life, had exclusively breastfed and the parents had disclosed their HIV status to the spouses.

Mixed feeding should be discouraged for all HIV positive mothers because of its associated risk of infant HIV infection. Mothers should be encouraged to exclusively breastfeed their infants and HIV testing and disclosure of spouses should be promoted. Further research is recommended to examine the influence of partner disclosure of HIV status on HIV infection of children.

\section{Acknowledgements}

Special thanks to the HIV positive mothers and their infants who participated in the study, Dr. Julius Kasozi, Maureen Muchwa and the affiliation institutions -Mildmay Uganda, International Health Sciences University and Uganda Christian University.

\section{References}

[1] The Joint United Nations Programme on HIV/AIDS, 2011. http://files.unaids.org/en/media/unaids/contentassets/documents/e pidemiology/2012/gr2012/20121120_FactSheet_Global_en.pdf

[2] UNAIDS HIV/AIDS Fact sheet. 2016 http://www.unaids.org/sites/default/files/media_asset/UNAID S_FactSheet_en.pdf

[3] United Nations. UN General Assembly Special Session report, 2010 .

[4] Ministry of Health. Uganda Population-Based HIV Impact Assessment.2017.
[5] Mildmay Uganda 2010/2011 annual report. 2012.

[6] Mildmay Annual Impact report. 2016. https://www.mildmay.org/wpcontent/uploads/2013/07/MildmayAR2016_FINAL.pdf

[7] The Joint United Nations Programme on HIV/AIDS, Annual report 1997. 1998.

[8] World Health Organisation. Programming for male involvement in reproductive health. Report of the meeting of WHO. WHO/PAHO, Washington DC, USA. 2001.

[9] The Joint United Nations Programme on HIV/AIDS, Annual report. 2009.

[10] Chilongozi D, Wang L, Brown L, et al. Morbidity and mortality among a cohort of human immunodeficiency virus type 1-infected and uninfected pregnant women and their infants from Malawi, Zambia, And Tanzania. Pediatr Infect Dis J. 2008; 27: 808-814.

[11] Pitt J, Brambilla D, Reichelderfer P, Landay A, Mcintosh K, Burns D, Hillyer Gv, Mendez H, Fowler Mg, 1997. Maternal immunologic and virologic risk factors for infant human immunodeficiency virus type- 1 infection: findings from the women and infant transmission study. J infect dis. 1997 mar; 175 (3):567-75. Department Of Pediatrics, Columbia University College Of Physicians And Surgeons, New York City, NY 10032, USA.

[12] Newell Ml, Coovadia H, Cortina-Borja M, et al. Mortality of infected and uninfected infants born to hiv-infected mothers in Africa: a pooled, analysis. Lancet. 2004; 364:1236-1243.

[13] Atashili J, Kalilani L, Seksaria V, et al. Potential impact of infant feeding recommendations on mortality and hivinfection in children born to HIV infected mothers in Africa: a simulation. BMC infect dis. 2008; 8:66.

[14] Jaana Auvinen, Tarja Suominen \& Maritta Välimäki, Male participation and prevention of human immunodeficiency virus mother-to-child transmission in Africa, psychology, Health \& Medicine, 15:3, 288-313. 2010.

[15] Kelsey Jl, Whittemore As, Evans As, Thompson Wd.,. Methods in observational epidemiology. 1996. Oxford University Press.

[16] Magoni M, Bassani L, Okongo P, Kituuka P, Germinario Ep, Giuliano M, Vella S. Mode of infant feeding and HIV infection in children in a program for prevention of mother to child transmission in Uganda. AIDS. 2005 Mar 4; 19(4):433-7.

[17] Coutsoudis A, Pillay K, Spooner E, Kuhn L, Coovadia Hm. Influence of infant-feeding patterns on early mother to child transmission of HIV-1 in Durban, South Africa: a prospective cohort study. South African vitamin A study group. Lancet. 1999 Aug 7; 354(9177):471-6.

[18] Marangwanda et al, Abstract No. D11905. Woman's disclosure of HIV status: a criticalcomponent of the PMTCT intervention.

[19] Bii Sc, Otieno-Nyunya B \& Siika A. Infant feeding practices among HIV infected women receiving prevention of mother-to-child transmission services at Kitale District Hospital, Kenya. East Afr Med J. 2008; 85:156-161. 